Nigerian Journal Of Physiological Sciences 21 (1-2): 27-30 @ Physiological Society Of Nigeria, 2006

Available online/abstracted at http://www.biolineinternational.org.br/njps; www.ajol.info/journals.njps; www.cas.org

\title{
EFFECTS OF EXTRACELLULAR ZINC ION ON THE RATE OF OXYGEN CONSUMPTION OF RAT BRAIN MITOCHONDRIA
}

\author{
B. I. KUKOYI \\ OCBS/Molecular Cell Biology, University of Maryland, Baltimore, Dental School., USA
}

Summary: The inhibitory effect of extracellular zinc ion on the rate of oxygen consumption of rat brain mitochondria pre-incubated in $1.0 \mathrm{mM} \mathrm{Ca}{ }^{2+}$ EDTA were determined. There was a significant increase $[\mathrm{P}<0.01]$ in the rate of oxygen consumption in the rat brain mitochondria pre-incubated in $1.0 \mathrm{mM}$ $\mathrm{Ca}^{2+}$ EDTA in a succinate initiated reaction. The reverse was the case when the concentration of $\mathrm{Ca}^{2+} \mathrm{EDTA}$ was increased to $10 \mathrm{mM}$. A $20 \mu \mathrm{M}$ zinc-aspartate was found to have no inhibitory effect on the rate of oxygen consumption of the brain mitochondria pre-incubated with $1.0 \mathrm{mM} \mathrm{Ca}{ }^{2+}$ EDTA when compared with the control that lacked $1.0 \mathrm{mM} \mathrm{Ca}{ }^{2+} E D T A$, however there was a significant decrease $[\mathrm{P}<0.01]$ in the rate of oxygen consumption of the rat brain mitochondria in the control experiment.

Key Words: Zinc, brain mitochondria, oxygen consumption.

\section{Introduction}

Numerous studies have shown that zinc is one of the most prevalent trace elements found in the brain, where it is primarily retained in the hippocampus (Crawford and Connor, 1972). In fact, levels of zinc in hippocampal area are greater than those of any other elements including calcium (Kemp and Danscher, 1979). However, excessive exposure to extracellular zinc can damage central neurons.

(Jae-Young et al,_1996). Damage to the brain cells could be prevented by the intraventricular injection of a zinc chelating agent. For physiological relevancy, any studies relating to the intracellular effect of zinc on mitochondrial function must involve zinc forms and concentrations that would reflect the cellular composition of zinc. This is evident in the fact that in biological systems, very little, if any, zinc is free in solution (Vallee and Falchuk, 1993). Estimates place the total cellular zinc content of mammalian cells at approximately $0.2 \mathrm{mM}$ (Outten and O'Halloran, 2001). However, the cytosolic concentration of free zinc ions is estimated to be in the $\mathrm{nM}$ - fM range, i.e. a negligible pool of zinc (Outten and O'Halloran, 2001). Of the total cellular zinc, about $50 \%$ is cytoplasmic which provides the available pool of zinc for effects on mitochondrial function. In the absence of free zinc ions, essentially all the cytosolic zinc exists bound to mobile low molecular weight ligands $(\sim 10 \%)$ which could provide the available zinc pool for mitochondrial interaction. The outer mitochondrial membrane pore structure permits the passage of molecules up to $\sim 10 \mathrm{kDa}$; so that molecules of this size and smaller would constitute the low molecular weight zinc ligands for the delivery of zinc into the intermembrane space. This potential pool of zinc donors for interaction within the mitochondria would approximate a low $\mu \mathrm{M}$ range.

This study focus on the effects of extracellular zinc on the rate of oxygen consumption with special emphasis on rat brain mitochondria pre-incubated in Calcium-EDTA. Calcium-EDTA is an extracellular zinc chelator and has a higher affinity for calcium ion at physiologic $\mathrm{pH}$ than for magnesium ion, but it has a much higher affinity for zinc ion than calcium or magnesium ions. Thus, CalciumEDTA binds extracellular zinc without reducing extracellular calcium ions.

\section{Materials and Methods}

Young adult male Wistar rats weighing between 250-300 grams were employed as the source of brain and mitochondrial preparations. The handling and treatment of the animals were in conformity with the National Institute of Health [NIH] and University of Maryland guidelines for the care and use of animals for research. The rats were sacrificed and the brains removed and placed in isolation buffer solution containing $250 \mathrm{mM}$ Sucrose, $10 \mathrm{mM}$ HEPES and 
1 mM EDTA, pH 7.30. The preparation of mitochondria has been described previously [Kukoyi et al, 2004)]. All procedures were carried out at 2-4 $0 \mathrm{C}$ on ice. Generally, rat brain tissue were chopped into $1 \mathrm{~mm}$ pieces in isolation buffer $[250 \mathrm{mM}$ sucrose, $10 \mathrm{mM}$ HEPES and $1 \mathrm{mM}$ EDTA, pH 7.30], homogenized in a motor-driven glass homogenizer, and centrifuge at $500 \mathrm{x} \mathrm{g}$ for 5 minutes in a refrigerated Beckman preparative ultracentrifuge. The supernatant fluid was centrifuge for 7 minutes at $12000 \mathrm{x} \mathrm{g}$ and the resulting pellet was washed twice in isolation buffer containing $0.25 \%$ dialyzed fatty acid free bovine serum albumin (BSA), and washed once in zinc uptake reaction buffer $[250 \mathrm{mM}$ sucrose, $10 \mathrm{mM}$ HEPES and $5 \mathrm{mM} \mathrm{KH2PO} 4$ ]. The final mitochondrial pellets were suspended in reaction buffer and adjusted to provide a mitochondrial concentration around $20 \mathrm{mg}$ protein ml-1. Protein assay was performed by a method of Bradford [1976]. The condition of the mitochondrial preparations was checked by determination of oxygen consumption and respiratory control with the aid of a fiber optic oxygen monitoring system [Fiber Optic Oxygen Monitor Model 210]. Preparations that did not meet the criteria of no detectable endogenous respiration and succinate-stimulated respiratory control ratio $>2.5$ were generally excluded from the studies.

Zinc-lingand solution was prepared to provide a zinc/lingand molar ratio of 1:3. This served as a source of free Zinc ions, viz: zincaspartate. Zinc-aspartate solution was dissolved in medium containing $250 \mathrm{mM}$ sucrose and 10 mM HEPES, pH 7.30. Generally $75 \mu$ of brain mitochondrial suspension containing $250 \mu$ mitochondrial proteins was added to $75 \mu \mathrm{l}$ reaction buffer containing $20 \mu \mathrm{M}$ Zinc-aspartate. This reacting system was incubated at $37 \mathrm{oC}$ with $1 \mathrm{mM}$ of $\mathrm{Ca}$ 2EDTA for five minutes while the control experiment lacked $1 \mathrm{mM} \mathrm{Ca}+2$ EDTA., The rate of oxygen consumption of the brain mitochondria incubated with $1 \mathrm{mM}$ of $\mathrm{Ca}+2 \mathrm{EDTA}$ for five minutes was determined using Fiber Optic Oxygen Monitor Model 210 with $50 \mathrm{mM}$ succinate as substrate. Inhibition of oxygen consumption by $20 \mu \mathrm{M}$ zinc-aspartate was measured. The reaction was initiated by the addition of $50 \mathrm{mM}$ succinate. The rate of oxygen consumption was monitored, and $2 \mu \mathrm{M}$ of ADP were added to complete the reaction.

In another experiment the brain mitochondria were incubated with $10 \mathrm{mM}$ $\mathrm{Ca}+2 \mathrm{EDTA}$, and the rate of oxygen consumption was determined with succinate as substrate. The control experiment lacked $10 \mathrm{mM} \mathrm{Ca}+2 \mathrm{EDTA}$.

The incubation and inhibitory effects of zinc-aspartate on the oxygen consumption of the brain mitochondria were repeated two times to ensure the reproducibility of the results. The data were analyzed by Sigma 8.0. The representative results are presented.

\section{Results}

Figure 1 shows the oxygen monitor tracing of succinate stimulated rate of oxygen consumption of brain mitochondria in incubated medium (incubated in $1 \mathrm{mM} \mathrm{Ca}+2 \mathrm{EDTA}$ ). There was a significant increase in oxygen consumption when the substrate $\mathrm{Zn}+2$-aspartate were added to the reacting medium in contrast to the control in which $1 \mathrm{mM} \mathrm{Ca+2EDTA}$ is lacking.

Table I shows a significant increase $[\mathrm{P}<0.01]$ in the rate of oxygen consumption in the rat brain mitochondria pre-incubated in 1.0 $\mathrm{mM} \mathrm{Ca}+2$ EDTA compared to the control experiment that lacked $1.0 \mathrm{mM} \mathrm{Ca+2EDTA.}$ Extracellular zinc [zinc-aspartate] has no inhibitory effect on the rate of oxygen consumption in the rat brain mitochondria incubated in $1.0 \mathrm{mM} \mathrm{Ca+2EDTA.} \mathrm{The}$ inhibitory effect of zinc aspartate is significant $[\mathrm{P}<0.01]$ in the control experiment that lacked $1.0 \mathrm{mM} \mathrm{Ca}+2 \mathrm{EDTA}$.

The rate of oxygen consumption in the rat brain mitochondria incubated in $10.00 \mathrm{mM}$ $\mathrm{Ca}+2$ EDTA decreased significantly $[\mathrm{P}<0.01]$ compared to the control that lacked $10.00 \mathrm{mM}$ $\mathrm{Ca}+2 \mathrm{EDTA}$ [Figure 2]. 
Extracellular zinc inhibits brain mitochondria oxygen consumptions

Table I : Effect of zinc ions on the oxygen consumption of brain mitochondria preincubated with $1 \mathrm{mM}$ Ca+2-EDTA.

\begin{tabular}{lcc}
\hline & Succinate & Zinc-aspartate \\
\hline $\begin{array}{l}\text { Control [-Ca+2EDTA] } \\
\text { Experimental }\end{array}$ & $0.55 \pm 0.05$ & $0.30 \pm 0.03$ \\
{$[+\mathrm{Ca}+2 \mathrm{EDTA}]$} & $0.88 \pm 0.06^{*}$ & There was no effect \\
\hline
\end{tabular}

Units of the rate of oxygen consumption are in microliter of oxygen consumed per minute per milligram protein. Each value represents the mean \pm S. E for five observations.

* Significant difference from control.

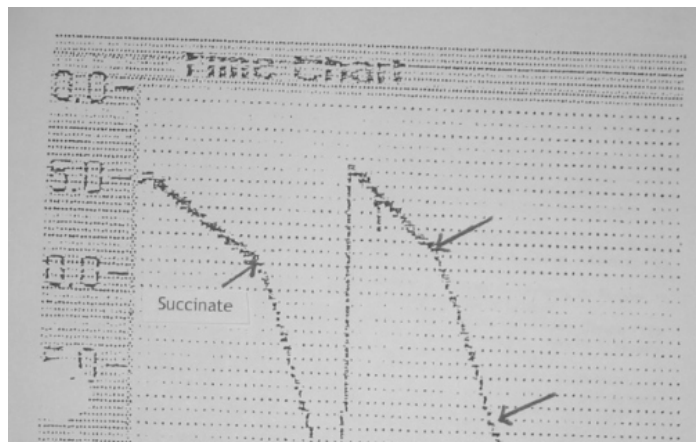

FIGURE 1: Oxygen monitor tracing of succinate stimulated rate of oxygen consumption of brain mitochondria incubated in $1 \mathrm{mM}$ Calcium-EDTA and in control (without Calcium-EDTA)

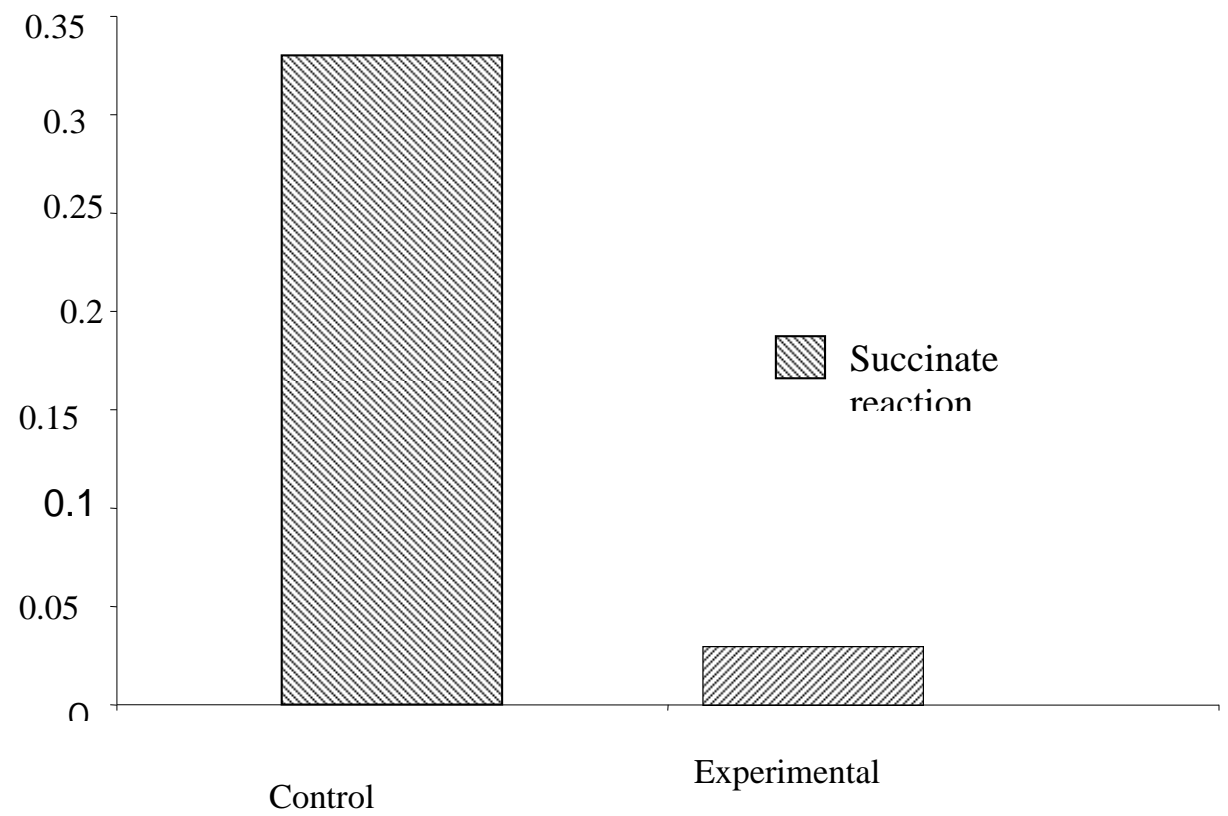

Figure 2. Effect of $10 \mathrm{mM}$ of $\mathrm{Ca}+$ EDTA on the rate of oxygen consumption of the rat brain mitochondria 


\section{Discussion}

It has been reported that exposure of the brain to excessive extracellular zinc is neurotoxic to the brain cells; this toxicity may be mediated in part by zinc influx into the brain cells (JaeYoung Koh et al, 1996). This experiment shows that extracellular zinc ions have no inhibitory effect on the rate at which the rat brain mitochondria incubated in $\mathrm{Ca}^{2+}$ EDTA consumed oxygen (Table 1 ). The $\mathrm{Ca}^{2+}$ EDTA are reported to chelate zinc and also have higher affinity for zinc, hence bind extracellular $\mathrm{Zn}^{2+}$ and protect the brain from being damage by reducing extracellular zinc ions [Horning and Trombley, 2001]. Some effects of chelating agents upon mitochondria could be explained in terms of removal of traces of zinc ions normally present in mitochondria or absorbed from the components of homogenate during isolation procedure. There was a significant increase in the rate of oxygen consumption in the rat brain mitochondria incubated in $\mathrm{Ca}^{2+}$ EDTA compared to the control that lacked the protection of $\mathrm{Ca}^{2+}$ EDTA (Figure 1). $\mathrm{Ca}^{2+}$ EDTA chelates not only the zinc ions but other enzyme co-factors including magnesium ions [Jae-Young et al 1996]. When $1 \mu \mathrm{M}$ of Magnesium Sulfate was added to the experimental medium, the rate at which oxygen consumed was increased ( the data not shown).The lack of cytoprotection was seen when the brain mitochondria was incubated with $10 \mathrm{mM} \mathrm{Ca}^{2+}$ EDTA and the rate of oxygen consumption was measured. There was a significant $[\mathrm{P}<0.01]$ decrease in the rate at which oxygen was consumed presumably due to the chelation of all the enzyme co-factors that affect respiratory enzymes i.e. $\mathrm{Mg}{ }^{2+}, \mathrm{Cu}^{2+}$ and $\mathrm{Fe}^{3+}$. Jae-Young et al [1996] further reported that $\mathrm{Ca}^{2+}$ EDTA meaningfully reduced extracellular Magnesium ions. With the addition of I.0 mM $\mathrm{MgSO}_{4}{ }^{-}$to the reaction, $\mathrm{Mg}^{2+}$ stimulates the affected oxygen consumption of the rat brain mitochondria by increasing the rate.

\section{References}

Bradford, M. M. (1976). Rapid and sensitive method for quantitation of microgram quantities of rotein utilizing the principle of protein-dye binding. Anal. Biochem. 72, 248-254.

Crawford, I. L. and Connor, J. D. (1972). Zinc in maturing brain: hippocampal concentration and localization. J. Neurochem. 19:14511458.

Horning, M. S. and Trombley, P. Q.. (2001). Zinc and Copper influence excitability of rat olfactory bulb neurons by multiple mechanisms. J. Neurophysiol. 86:16521660.

Jae-Young Joh, Sang W. Suh, Byoung J. Gwag, Yong Y. He, Chung Y. Hsu, Dennis W. Choi. (1996). The role of zinc in selective neuronal death after transient global cerebral Ischemia. Science. 272:1013-1016.

Kemp, K and Damscher, G. (1979). Multielement analysis of the rat hippocampus by proton induced $\mathrm{x}$-ray emission specteroscopy (Phosphorus, Calcium, Iron, Zinc, Copper, Lead Bromine and Ribidium). Histochemistry, 159:169-176.

Kukoyi, B. I., Costello, L. C. and Franklin, R. B. (2004). The effect of exogenous zinc ions on the pattern of oxygen consumption of hepatic mitochondria of albino rats. Afr. $J$. Med. Med. Sc. 33:361-363.

Outten, C. E. and O'Halloran, T. V. (2001). Femtomolar sensitivity of metalloregulatory proteins controlling zinc homeostasis. Science 292: 2488-2492.

Vallee, B. L. and Falchuk, K. H. (1993). The biochemical basis of zinc physiology. Physiol. Rev. 73: 79-118

Received: $25 / 8 / 06$

Accepted: 19/11/06 